\title{
Rad53 regulates replication fork restart after DNA damage in Saccharomyces cerevisiae
}

\author{
Shawn J. Szyjka, Jennifer G. Aparicio, Christopher J. Viggiani, Simon Knott, Weihong Xu, ${ }^{1}$ \\ Simon Tavaré, and Oscar M. Aparicio ${ }^{2}$ \\ Molecular and Computational Biology Program, University of Southern California, Los Angeles, California 90089, USA
}

\begin{abstract}
Replication fork stalling at a DNA lesion generates a damage signal that activates the Rad53 kinase, which plays a vital role in survival by stabilizing stalled replication forks. However, evidence that Rad53 directly modulates the activity of replication forks has been lacking, and the nature of fork stabilization has remained unclear. Recently, cells lacking the Psy2-Pph3 phosphatase were shown to be defective in dephosphorylation of Rad53 as well as replication fork restart after DNA damage, suggesting a mechanistic link between Rad53 deactivation and fork restart. To test this possibility we examined the progression of replication forks in methyl-methanesulfonate (MMS)-damaged cells, under different conditions of Rad53 activity. Hyperactivity of Rad53 in pph3s cells slows fork progression in MMS, whereas deactivation of Rad53, through expression of dominant-negative Rad53-KD, is sufficient to allow fork restart during recovery. Furthermore, combined deletion of PPH3 and PTC2, a second, unrelated Rad53 phosphatase, results in complete replication fork arrest and lethality in MMS, demonstrating that Rad53 deactivation is a key mechanism controlling fork restart. We propose a model for regulation of replication fork progression through damaged DNA involving a cycle of Rad53 activation and deactivation that coordinates replication restart with DNA repair.
\end{abstract}

[Keywords: DNA replication fork; DNA damage; DNA repair; cell cycle checkpoint; BrdU; phosphatase; microarray]

Supplemental material is available at http://www.genesdev.org.

Received February 6, 2008; revised version accepted May 14, 2008.

S phase is a particularly vulnerable period for the genome as environmental agents that damage DNA and intrinsic replication defects can interfere with the replication process, potentially giving rise to mutations and genomic instabilities. The presence of DNA damage during chromosomal DNA replication results in a significantly reduced rate of DNA synthesis in organisms ranging from bacteria to humans. In Saccharomyces cerevisiae, the slowed S phase resulting from DNA alkylation by methyl-methanesulfonate (MMS) depends on checkpoint signaling by Mec1 and Rad53, indicating that slowing of DNA synthesis is a regulated process (Paulovich and Hartwell 1995; Paulovich et al. 1997). Similar radioresistant DNA synthesis occurs in mammalian cells lacking the Mec1-related protein ATM (Painter and Young 1980). The exquisite DNA damage sensitivity of checkpoint defective cells, and the increased cancer susceptibility of

\footnotetext{
${ }^{1}$ Present address: Stanford Genome Technology Center, Stanford University, Palo Alto, CA 94304, USA.

${ }^{2}$ Corresponding author.

E-MAIL oaparici@usc.edu; FAX (213) 740-8631.

Article is online at http://www.genesdev.org/cgi/doi/10.1101/gad.1660408.
}

organisms with checkpoint defects, emphasizes the importance of these surveillance mechanisms (for review, see Kolodner et al. 2002).

Generation of a DNA damage signal during $S$ phase requires activation of replication forks (Shimada et al. 2002; Tercero et al. 2003), suggesting that the encounter of replication forks with damaged sites creates aberrant DNA structure(s), such as excess ssDNA, which is recognized by checkpoint sensors (for review, see Paulsen and Cimprich 2007). In S. cerevisiae, MMS-induced DNA damage leads to recruitment of Mec1 kinase and the PCNA-like Rad17-Ddc1-Mec3 complex to sites of damage, whereupon these proteins further engage Rad9, which mediates Mec1-dependent phosphorylation of the effector kinases Chk1 and Rad53 (for review, see Melo and Toczyski 2002). Chk1 and Rad53 target downstream factors to delay mitotic progression, and Rad53 additionally targets factors to induce expression of DNA metabolism genes, stimulate deoxyribonucleotide triphosphate (dNTP) production, suppress the initiation of additional (late-firing) replication origins, and stabilize the function of replication forks.

Activation of $\operatorname{Rad} 53$ is critical for survival of yeast 
cells subjected to DNA damage or replication stress (for review, see Branzei and Foiani 2006). In the absence of Rad53 (or Mec1), MMS treatment does not slow S phase and DNA content approximately doubles; however, these cells are inviable (Paulovich and Hartwell 1995). Analysis of an individual replicon reveals a significant degree of incomplete replication, suggesting that repli-

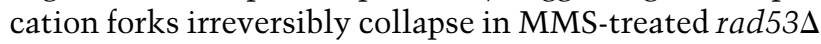
and mec1s cells (Tercero and Diffley 2001). Recovery of cells from inhibition of DNA synthesis with hydroxyurea $(\mathrm{HU})$ also requires Rad53, as HU-stalled replication forks degenerate in rad53 $\Delta$ cells and these cells are unable to resume DNA synthesis after removal of the drug (Desany et al. 1998; Lopes et al. 2001; Sogo et al. 2002). These studies have led to the paradigm that a critical function of Rad53 in the S-phase checkpoint pathways is the stabilization of stalled or stressed replication forks (Branzei and Foiani 2006).

The role of Rad53 in stabilization of stressed forks and the Rad53 dependence of $S$ phase slowing in response to DNA damage implies that fork stabilization by Rad53 involves direct inhibition of the replication fork. However, careful analysis of DNA synthesis across a wellcharacterized chromosome VI replicon indicates that whereas replication forks progress slowly due to the presence of MMS, they nevertheless progress with simi-

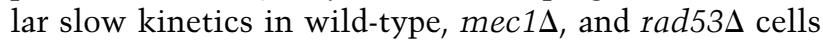
(Tercero and Diffley 2001). These findings have suggested that Mec1 and Rad53 do not regulate fork progression as a consequence of replication fork stabilization, and further that replication initiation of normally dormant and late-firing origins must account for the accelerated S phase of rad53 $\Delta$ and mec $1 \Delta$ cells. Indeed, analysis of cells carrying the hypomorphic mec1-100 allele supports this idea (Paciotti et al. 2001; Tercero et al. 2003). These cells fail to restrain late origin firing and do not slow replication in MMS; however, mec1-100 cells remain viable and show minimal evidence of fork dysfunction in MMS, suggesting that fork stabilization operates normally. Thus, defective fork stabilization correlates with drug sensitivity, whereas deregulation of origin firing correlates with the failure to slow $\mathrm{S}$ phase.

The conclusion that Rad53 does not directly modulate the rate of fork progression is challenged by the recent characterization of cells lacking the Psy2-Pph3 phosphatase, which acts to dephosphorylate, and hence deactivate, Rad53 during recovery from MMS exposure (O'Neill et al. 2007). After transient exposure to MMS during early S phase, $p s y 2 \Delta$ and $p p h 3 \Delta$ cells are delayed in completing bulk DNA replication, and analysis of BrdU incorporation along the aforementioned chromosome VI replicon indicates that replication fork progression is delayed in the absence of Psy2-Pph3. The correlation between the delayed replication restart and delayed dephosphorylation of Rad53 suggests that deactivation of $\operatorname{Rad} 53$ is required for replication restart following DNA damage. The failure to dephosphorylate $\gamma \mathrm{H} 2 \mathrm{a}$ after DNA damage does not account for the replication restart defect of psy2 $2 \Delta$ or pph3 $3 \Delta$ cells (Keogh et al. 2006; O'Neill et al. 2007). Nevertheless, the possibility remains that the role of Psy2-Pph3 in replication fork restart reflects dephosphorylation of a different, still unrecognized, Psy2-Pph3 substrate.

In this study, we tested the hypothesis that Rad53 controls replication fork restart by monitoring the progression of replication forks in MMS-damaged cells, under different conditions of Rad53 activity. We show that replication forks progress more slowly in pph $3 \Delta$ cells in the presence of MMS, and in cells recovering from MMS damage. In contrast, antagonism of Rad53 activity in these $p p h 3 \Delta$ cells restores rapid DNA synthesis at forks during recovery, indicating that deactivation of Rad53 is sufficient to allow fork restart. We also reveal the involvement of Ptc2 in dephosphorylation of Rad53 in MMS-treated pph3s cells, explaining how these cells eventually complete DNA synthesis and resume growth, and further supporting the connection between Rad53 deactivation and replication restart. These results provide important new insights into the mechanism of replication fork stabilization and restart as well as coordination with DNA repair.

\section{Results}

Pph3 is required for replication fork progression through damaged DNA

To examine the role of Rad53 in regulation of replication fork dynamics on a damaged DNA template, we analyzed replication fork activity in $p p h 3 \Delta$ cells, which lack the Rad53 phosphatase, Psy2-Pph3. Previous work showed that cells lacking $P P H 3$ or PSY2 replicate normally in the absence of DNA damage, but are delayed in completing replication during recovery from MMS-induced DNA damage, suggesting a defect in replication fork restart (O'Neill et al. 2007). To obtain a comprehensive view of replication fork dynamics, we monitored replication of two well-characterized expanded replicons on chromosomes III and VI (Labib et al. 2000; Tercero and Diffley 2001; Szyjka et al. 2005), using improved methods for BrdU incorporation into S. cerevisiae (Viggiani and Aparicio 2006), immunoprecipitation of BrdUlabeled DNA (Katou et al. 2003; Szyjka et al. 2005), and analysis with oligonucleotide-tiling microarrays, which together we refer to as BrdU-IP-chip (see the Materials and Methods).

We began by comparing replication of wild-type and pph $3 \Delta$ cells during constant exposure to MMS. G1-synchronized cells were released from $\alpha$-factor arrest into rich medium containing $0.033 \%$ MMS; aliquots of this culture were exposed to BrdU for 15-min pulses and harvested for DNA isolation. BrdU incorporation occurs at the early origins ARS606 and ARS607 and at surrounding sequences during the 30 - to $45-\mathrm{min}$ pulse period, in both wild-type and pph3s cells (Fig. 1A). Little if any BrdU incorporation is detected at these origins subsequently. These results indicate that both strains initiate chromosomal DNA replication with similar dynamics, as demonstrated previously by analysis of replication initiation structures with two-dimensional (2D) gels $\left(\mathrm{O}^{\prime} \mathrm{Neill}\right.$ et al. 
Szyjka et al.

A

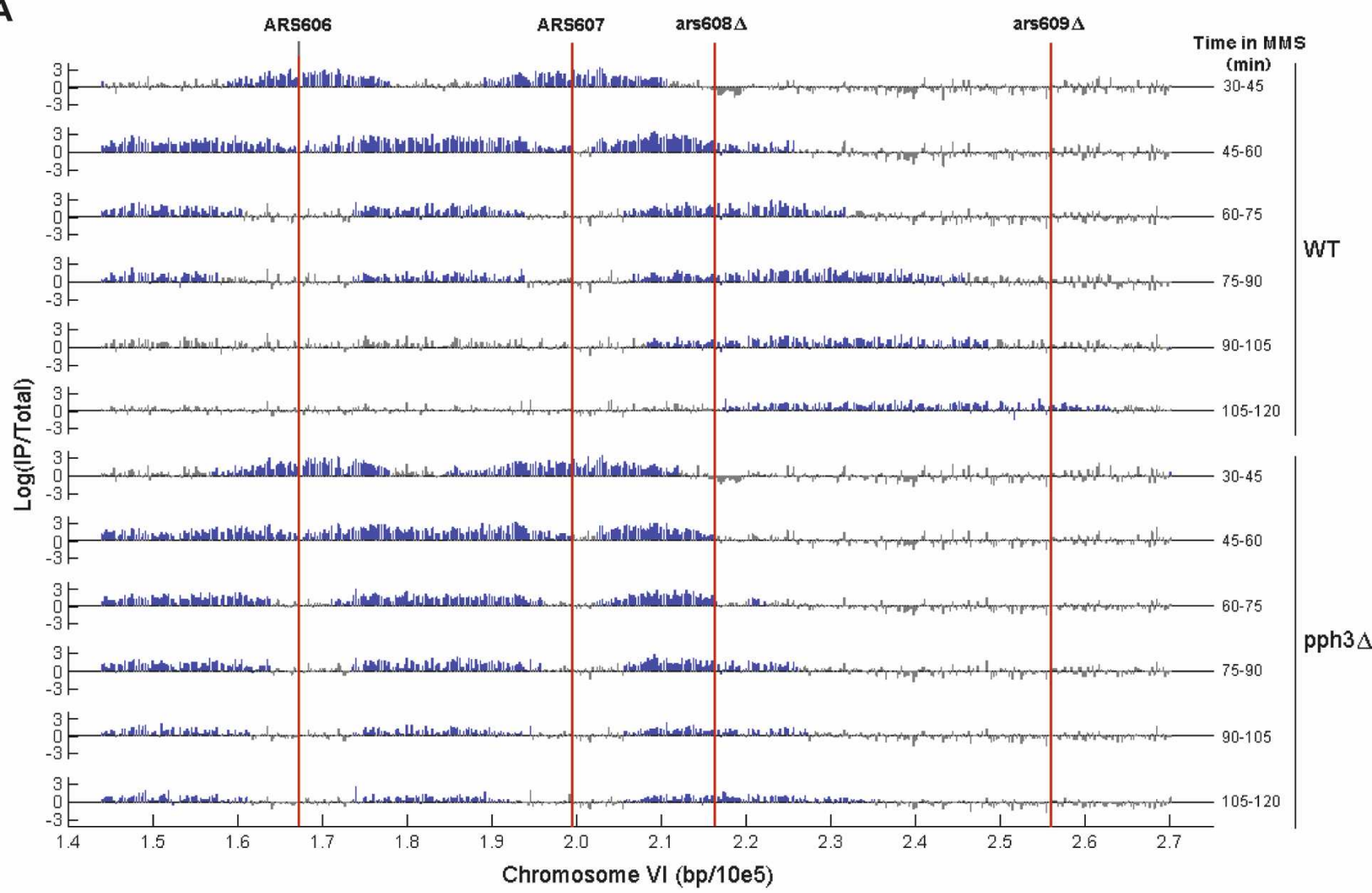

B

C

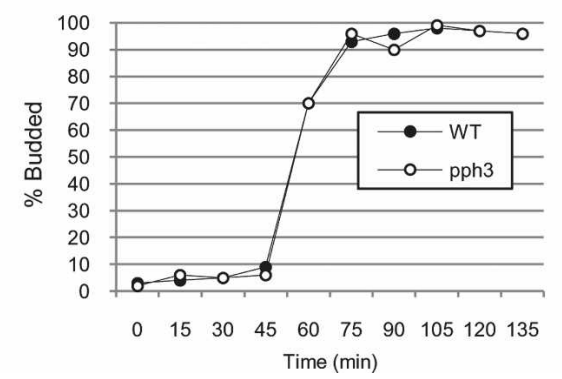

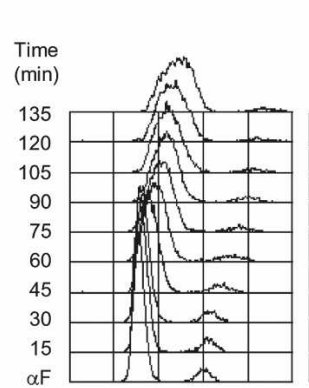

WT

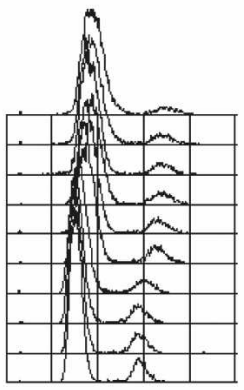

$\mathrm{pph} 3 \Delta$

Figure 1. $\quad$ PPH3 is required for progression of replication forks during constant MMS exposure. Wild-type (SSy419) and $p p h 3 \Delta(\mathrm{SSy} 420)$ cells were blocked in G1 phase with $\alpha$-factor and released synchronously into YEPD containing $0.033 \% \mathrm{MMS}$ at $23^{\circ} \mathrm{C}(\mathrm{Time}=0) .(A)$ Aliquots of each culture were incubated with BrdU for the indicated time intervals and harvested for BrdU-IP-chip analysis using an oligonucleotide-tiling array covering the indicated portion of chromosome VI. Probes representing statistically significant regions of BrdU incorporation were determined by a two-state Hidden Markov Model (Xu et al. 2006) and are highlighted in blue. Aliquots of each culture were harvested at the indicated times for determination of budding index $(B)$ and DNA content $(C)$.

2007). Analysis of budding kinetics also supports the conclusion that pph3s cells progress through the G1-S transition like wild-type cells (Fig. 1B). Thus, replication initiation at early origins appears normal in the absence of $P$ PH3.

The progression of replication forks away from ARS607 is impaired in the absence of PPH3. During the 45- to 60-min period, little BrdU incorporation is observed at ARS607. However, two flanking peaks of BrdU incorporation are observed, reflecting DNA synthesis at each replication fork emanating from ARS607 (Fig. 1A, the leftward-moving fork partially converges with the rightward-moving fork from ARS606). These patterns appear similar in wild-type and $p p h 3 \Delta$ cells; however, the rightward-moving ARS607 replication fork appears to progress $\sim 10 \mathrm{~kb}$ further from the origin in wild-type cells. The more distant progression of this replication fork in wild-type cells becomes more pronounced over the timecourse. By the 105- to 120-min interval, BrdU incorporation occurs over a large region of chromosome VI extend- 
ing $\sim 65 \mathrm{~kb}$ from ARS607 toward the telomere in wildtype cells, whereas BrdU incorporation in pph3s cells extends only $\sim 35 \mathrm{~kb}$ from ARS607. Wild-type cells also complete replication of the region between ARS606 and ARS607 by $\sim 90 \mathrm{~min}$, while BrdU incorporation in this region continues through $120 \mathrm{~min}$ in the pph3s cells.

The chromosome VI results are supported by analysis of the expanded chromosome III replicon, demonstrating limited progression of the leftward-moving replication fork from ARS306 in pph3s cells compared with wildtype cells (Supplemental Fig. S1). We used a data normalization method that allows us to make semiquantitative comparisons between hybridizations, and we note that pph3s cells reproducibly incorporate less BrdU than wild-type cells during each pulse (especially later times) based on the total area of BrdU enrichment (Fig. 1A; Supplemental Fig. S1; see below). The chromosome III and VI data are also consistent with the kinetics of bulk DNA synthesis as determined by DNA content analysis, with a higher rate of bulk DNA synthesis occurring in wild-type versus pph $3 \Delta$ cells (Fig. 1C). Together, these data clearly demonstrate limited progression of replication forks in MMS-treated pph3s cells, confirming a role for Pph3 in the function of replication forks encountering damaged DNA (O'Neill et al. 2007).

\section{Pph3 is required for restart of stalled replication forks} during DNA damage recovery

Cells lacking $\mathrm{PPH} 3$ also are delayed in resumption of DNA synthesis following removal of MMS, suggesting that continued presence of DNA damage is not the cause of delayed replication restart. To examine replication fork restart kinetics during DNA damage recovery, we released G1-synchronized cells into rich medium containing MMS for 60 min to allow early origin initiation and fork stalling, after which the MMS was quenched and washed out. BrdU-IP-chip analysis shows replication forks flanking ARS607 during the 45- to 60-min BrdU pulse in MMS in both wild-type and pph3s cells (Fig. 2A). Upon removal of MMS (Time $=0$ ), replication forks progress rapidly in wild-type cells with the leading edge of BrdU incorporation progressing $40 \mathrm{~kb}$ in $45 \mathrm{~min}$ (Fig. 2A), which is significantly more rapid than its replication during constant MMS exposure (comparing total time after G1 release) (Fig. 1A). In contrast, the leading edge of BrdU incorporation in pph3s cells progresses $\sim 20$ $\mathrm{kb}$ in $60 \mathrm{~min}$ (Fig. 2A).

Analysis of the expanded chromosome III replicon buttresses the chromosome VI results. The ARS306 replication fork exhibits limited progression during DNA damage recovery in $p p h 3 \Delta$ cells compared with wild type (Supplemental Fig. S2). Furthermore, bulk DNA synthesis during MMS recovery also is reduced significantly in pph $3 \Delta$ cells, consistent with the reduced progression and levels of BrdU incorporation in these cells (Fig. 2B; O'Neill et al. 2007). Together, these results strengthen and extend our previous conclusion that replication fork restart during DNA damage recovery requires $P P H 3$ (O'Neill et al. 2007).
Restoration of Pph3 function during DNA damage recovery enables rapid replication restart

Deregulation of Rad53 activity in pph3s cells by elimination of Pph3 function might disrupt the normal stabilization of forks, resulting in the observed defect in fork progression (Fig. 1A). However, a number of findings argue that replication forks are stable in pph3s cells, including relatively modest lethality in the presence of MMS and no evidence of the replication fork collapse observed in rad53 $\Delta$ cells by $2 \mathrm{D}$ gel analysis $\left(\mathrm{O}^{\prime} \mathrm{Neill}\right.$ et al. 2007). If forks indeed remain stable in $p p h 3 \Delta$ cells, we reasoned that restoration of $P P H 3$ function during recovery should enable rapid resumption of DNA synthesis.

To test the idea that stalled replication forks in $p p h 3 \Delta$ cells remain stable and capable of rapid restart, we placed the endogenous $P P H 3$ gene under control of the $G A L$ promoter to enable its induction subsequent to replication fork stalling by MMS. G1-synchronized wild-type, pph3s, and GAL-PPH3 cells grown in raffinose (to repress $G A L-P P H 3$ ) were released from arrest into raffinose medium containing MMS. After 90 min to allow initiation of early origins and stalling of replication forks, the cultures were split into fresh media lacking MMS and containing raffinose or galactose (to induce GAL-PPH3) (Fig. 3A). In raffinose or galactose, wild-type cells resume rapid DNA replication and complete bulk DNA synthesis between 120 and $180 \mathrm{~min}$ after removal of MMS, whereas pph $3 \Delta$ cells do not complete DNA synthesis by 240 min (Fig. 3B,C). In raffinose, GAL-PPH3 cells complete DNA synthesis with kinetics similar to $p p h 3 \Delta$ cells, demonstrating effective repression of $P P H 3$ activity (Fig. 3B). However, in galactose, GAL-PPH3 cells complete DNA synthesis by $180 \mathrm{~min}$, only slightly behind wild-type cells and significantly sooner than $p p h 3 \Delta$ cells (Fig. 3C). The $\sim 30$-min delay in replication restart of GAL-PPH3 cells compared with wild-type (Fig. 3C, cf. wild-type $90 \mathrm{~min}$ and $G A L-P P H 3120 \mathrm{~min}$ ) correlates with the time required to induce expression of $P P H 3$ from the GAL promoter (data not shown). The rapid restart of replication upon restoration of $P P H 3$ function is consistent with the conclusion that stalled replication forks in MMS-treated $p p h 3 \Delta$ cells are stable and poised for restart.

Deactivation of Rad53 is sufficient to restart stalled replication forks in pph $3 \Delta$ cells

The role of Pph3 in Rad53 deactivation by dephosphorylation implies that replication fork restart requires deactivation of Rad53. However, the role of Pph3 in replication restart may depend on dephosphorylation of other Pph3 substrates, either instead of, or in addition to Rad53. If Rad53 deactivation is the sole requirement for replication restart in pph $3 \Delta$ cells, then elimination of its activity during the DNA damage recovery period should enable fork restart. However, it is necessary to preserve Rad53 activity to stabilize forks encountering DNA damage during the initial period of MMS exposure. To exert this control over Rad53 activity, we used a domi- 
Szyjka et al.

A

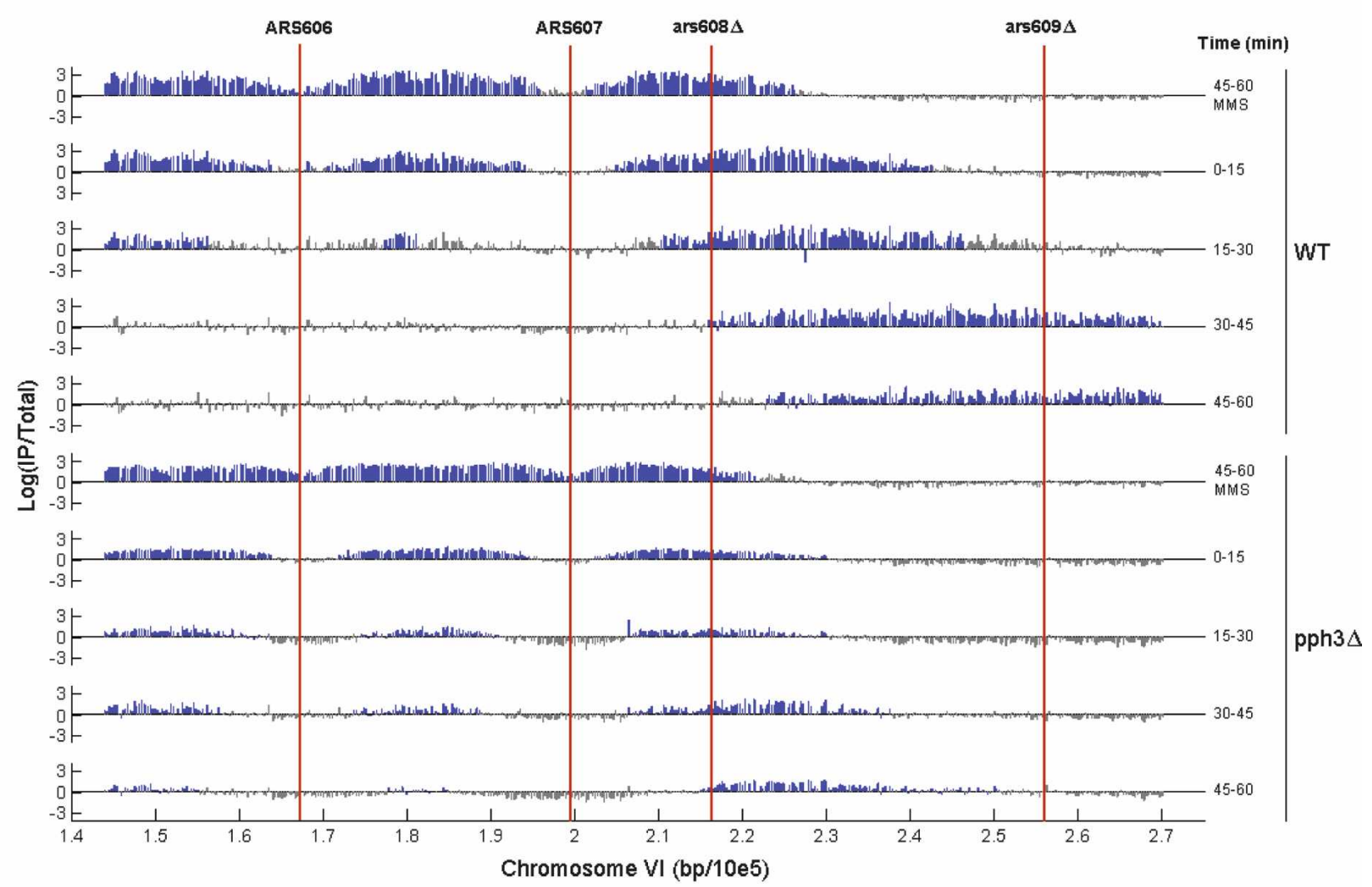

B

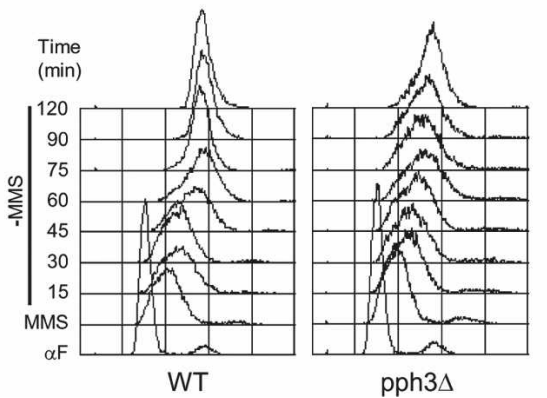

Figure 2. $P P H 3$ is required for replication fork restart during DNA damage recovery. Wild-type (SSy419) and pph3 $($ SSy420) cells were blocked in G1 phase with $\alpha$-factor and released synchronously into YEPD containing $0.033 \%$ MMS for $1 \mathrm{~h}$ at $23^{\circ} \mathrm{C}_{;}$MMS was washed out (Time $=0$ ), and cells were suspended in YEPD. (A) Aliquots of each culture were incubated with BrdU for the indicated periods and analyzed as described in Figure 1. $(B)$ Aliquots of each culture were harvested at the indicated times for DNA content analysis. (MMS) Samples are after $1 \mathrm{~h}$ of incubation with MMS.

nant-negative, kinase-dead allele of RAD53 (rad53$K 221 A, D 339 A$, herein referred to as rad53-KD), under control of the GAL promoter. Galactose-induced overexpression of Rad53-KD suppresses the kinase activity of previously DNA damage-activated, endogenous Rad53 (Pellicioli et al. 1999). Our approach was to expose pph3s cells to MMS to stall replication forks in the presence of wild-type, endogenous Rad53 and, following removal of MMS, to induce Rad53-KD to antagonize the activated, wild-type Rad53.

Antagonism of activated Rad53 by expression of Rad53-KD restores rapid replication kinetics during DNA damage recovery. Analysis of bulk DNA synthesis shows delayed completion of DNA replication after MMS damage in pph3s cells harboring empty vector (Fig. 4A). However, pph3s cells harboring pGAL-rad53KD completed DNA replication between 120 and 150 min after removal of MMS and addition of galactose. These replication kinetics are similar to those of wildtype cells recovering from MMS treatment (Fig. 4A, cf. Fig. 3B). We confirmed that endogenous Rad53 kinase activity is suppressed by overexpression of rad53-KD by in situ Rad53 kinase assay (Fig. 4B). Thus, artificial deactivation of Rad53 can replace Pph3 function in replication restart during DNA damage recovery, indicating that deactivation of Rad53 is the critical function of 
A

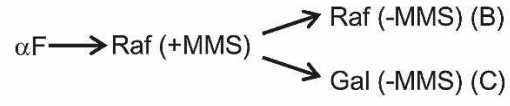

B

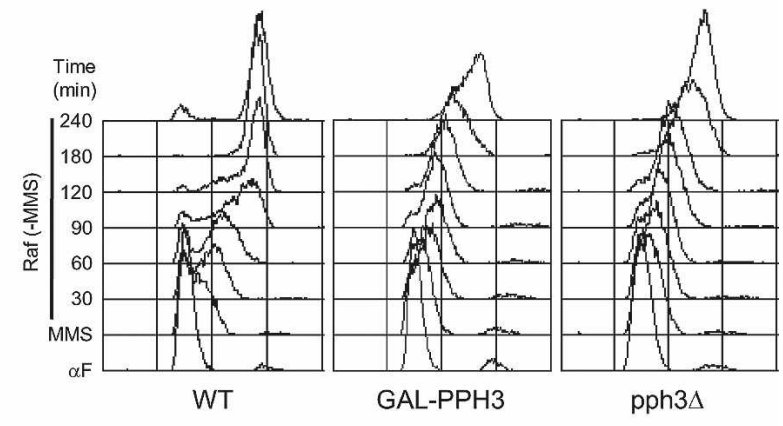

C

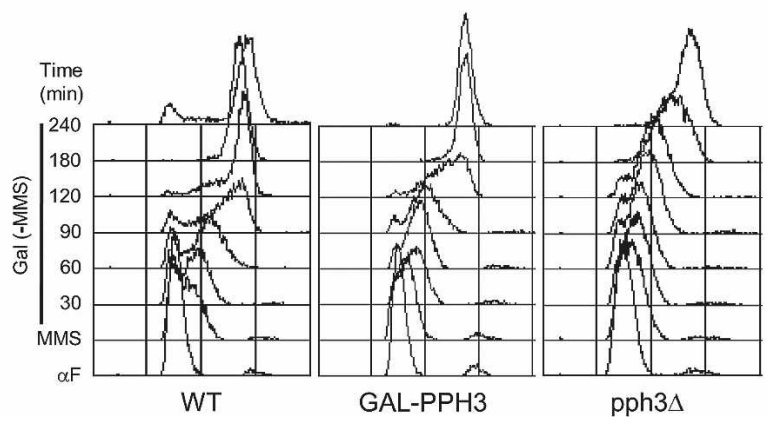

Figure 3. Restoration of $Р P H 3$ during DNA damage recovery facilitates replication restart. (A) Wild-type (SSy187), GALPPH3 (SSy250), and pph3D (SSy188) cells were blocked in G1 phase with $\alpha$-factor in YEP-Raffinose and released into YEPRaffinose containing $0.033 \% \mathrm{MMS}$ for $90 \mathrm{~min}$ at $23^{\circ} \mathrm{C}$. MMS was washed out (Time $=0$ ) and cells were split into YEP-Raffinose (RAF) $(B)$ and YEP-Raffinose $+0.5 \%$ Galactose $(\mathrm{GAL})(C)$. $(B, C)$ Cells were harvested at the indicated time points for DNA content analysis.

Pph3 in replication restart during DNA damage recovery. These results strongly suggest that Rad53 deactivation regulates replication restart.

To examine the effect of Rad53-KD expression specifically on replication fork restart, we used BrdU-IP-chip. In $p p h 3 \Delta$ cells harboring empty vector, very limited replication fork progression occurs during $2 \mathrm{~h}$ of recovery from MMS treatment (Fig. 4C). In contrast, pph3s cells expressing Rad53-KD exhibit accelerated replication fork progression. Rightward-moving replication forks reach the telomere during the 60 - to 90 -min pulse covering $30 \mathrm{~kb}$ during the 60 - to 90 -min pulse. Termination of the converging ARS606 and ARS607 replication forks occurs before the $60-$ to $90-\mathrm{min}$ interval, as minimal BrdU incorporation occurs in this region in cells expressing Rad53-KD. Analysis of chromosome III-L replication also shows accelerated replication fork restart resulting from Rad53-KD expression during DNA damage recovery in pph3s cells (Supplemental Fig. S3). These strains contain ARS305, and therefore the rightward ARS305 fork converges with the leftward ARS306 fork and replication termination occurs in the middle of this region between ARS305 and ARS306. While BrdU incorporation in the termination region continues through the 90to 120 -min period in pph3 $\Delta$ cells harboring only vector, $\mathrm{BrdU}$ incorporation in this region ceases before the 60- to 90-min interval in pph3s cells expressing Rad53-KD. Taken together, the replication fork kinetics of chromosome III and VI replicons, as well as the kinetics of bulk DNA replication, support the conclusion that deactivation of Rad53 regulates replication fork restart.

\section{Overlapping functions of Pph3 and Ptc2 in Rad53 deactivation and replication restart}

Our results strongly suggest that restart of DNA damagestalled replication forks requires Rad53 deactivation by Pph3. Nevertheless, pph3s cells eventually appear to complete chromosome replication during recovery from MMS based on bulk DNA content analysis ( $\mathrm{O}^{\prime} \mathrm{Neill}$ et al. 2007; see below). We determined the viability of $p p h 3 \Delta$ cells recovering from transient exposure to MMS, analogous to the earlier MMS recovery experiments. G1-synchronized cells were released into $\mathrm{S}$ phase in the presence of MMS and plated on rich medium lacking MMS to determine viability (Fig. 5A). Even after $3 \mathrm{~h}$ of MMS exposure, pph $3 \Delta$ cells show minimal loss of viability when permitted to recover, although the colonies appear somewhat smaller after longer exposure to MMS. These data indicate that $p p h 3 \Delta$ cells eventually complete chromosomal replication and resume proliferation and suggest that an alternative means exists for deactivation of Rad53.

The Ptc2 and Ptc3 phosphatases have been implicated in the dephosphorylation of Rad53 during prolonged recovery from a reparable dsDNA break or adaptation to an irreparable dsDNA break (Leroy et al. 2003). Hence, we tested the effect of deleting PTC2 (the major activity in dsDNA break recovery) on the viability of wild-type and pph3s cells subjected to transient MMS exposure (Fig. 5A). The ptc2s cells show no sensitivity to transient MMS exposure; however, ptc2 $\Delta$ pph $3 \Delta$ cells show sensitivity to acute MMS exposure, with $>10$-fold loss of viability per hour of MMS exposure. Given the previously characterized role of Ptc2 in Rad53 dephosphorylation after dsDNA breaks and the present data, we conclude that Pph3 and Ptc2 play overlapping roles in maintaining viability during recovery from MMS-induced DNA damage through deactivation of Rad53.

To confirm that the lethality caused by PTC2 deletion reflects its function as a Rad53 phosphatase, we analyzed Rad53 phosphorylation by immunoblotting. Wild-type, pph3s, ptc2s, and ptc2s pph3s cells were synchronized in G1 phase with $\alpha$-factor, released into S phase in the presence of MMS for $1 \mathrm{~h}$ to allow replication initiation and Rad53 activation, and then allowed to recover from MMS. All strains show hyperphosphorylated Rad53 after MMS treatment (Fig. 5B). Upon removal of MMS, wildtype cells show a decreasing proportion of hyperphos- 
Szyjka et al.

A

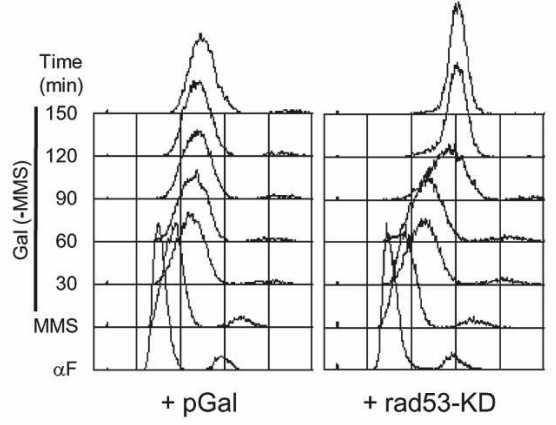

B

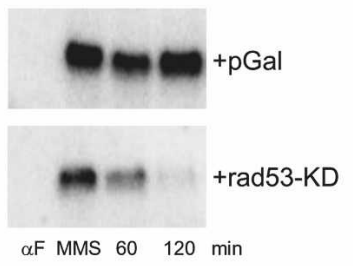

$\alpha \mathrm{F}$ MMS $60 \quad 120 \mathrm{~min}$

C

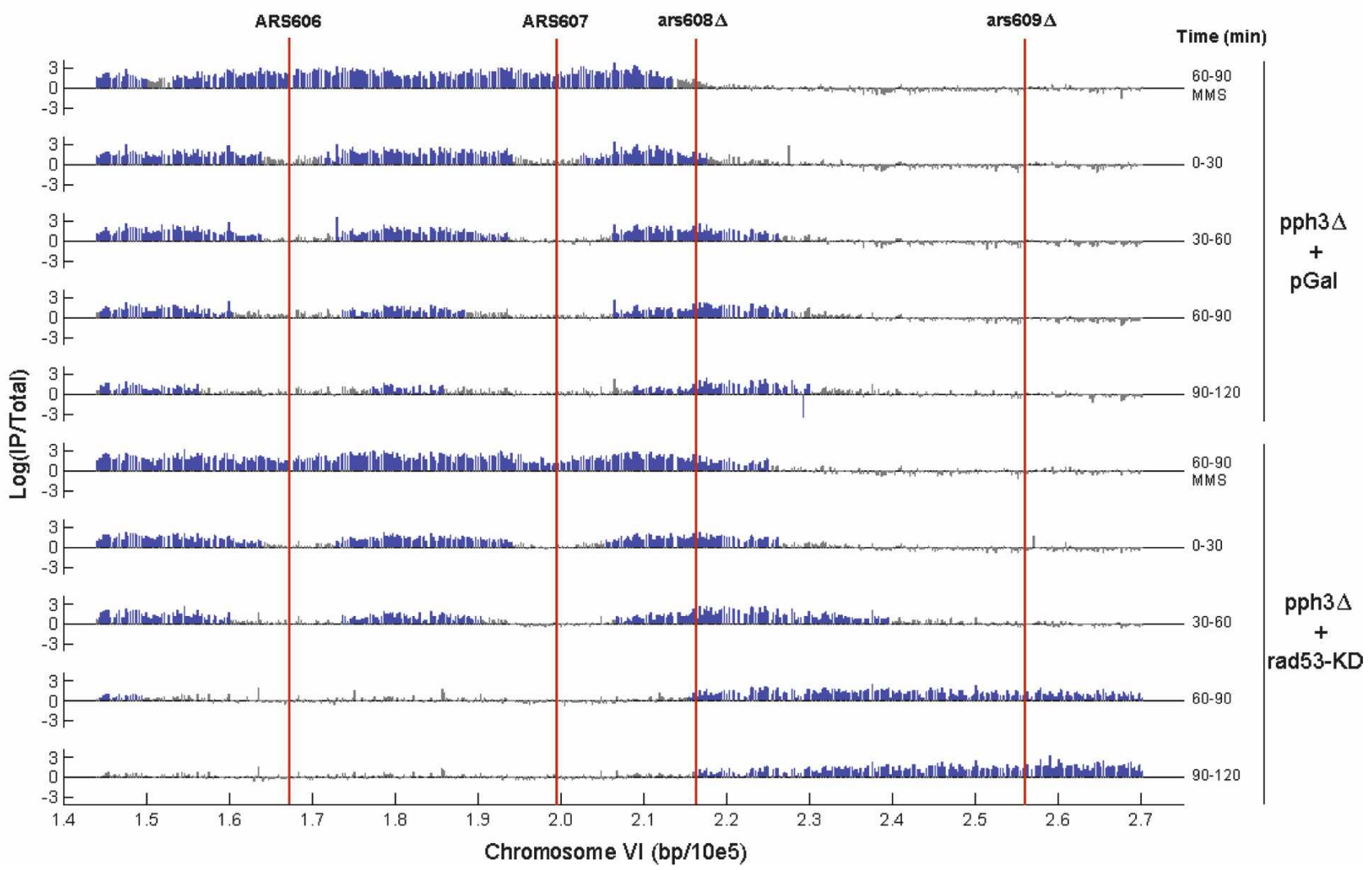

Figure 4. Antagonism of Rad53 promotes fork restart in pph3s cells recovering from MMS. pph3s cells transformed with pGal (SSy395) or pGal-rad53-KD (SSy396) were blocked in G1 phase with $\alpha$-factor in YEP-Raffinose and released into YEP-Raffinose containing $0.033 \%$ MMS for $90 \mathrm{~min}$ at $23^{\circ} \mathrm{C}$ (MMS). MMS was washed out (Time $=0$ ), and cells were suspended in YEP-Raffinose $+0.5 \%$ Galactose. Aliquots of each culture were harvested at the indicated times for DNA content analysis $(A)$ or in situ Rad53 kinase assay $(B)$, or were incubated with BrdU for the indicated periods and analyzed as described in Figure $1(C)$.

phorylated form(s) of Rad53, with the band corresponding to unphosphorylated Rad53 predominating by 2 h. A similar kinetic of Rad53 dephosphorylation occurs in ptc $2 \Delta$ cells, though there appears to be a slight delay $(\sim 30$ min) based on analysis of multiple experiments (Fig. 5B; data not shown). This result suggests that Ptc2 plays a minor role in Rad53 dephosphorylation during MMS recovery. As shown previously, pph3s cells are delayed in Rad53 dephosphorylation, with the hyperphosphorylated form(s) predominating for at least $2 \mathrm{~h}$ and remaining abundant for at least $4 \mathrm{~h}$. Consistent with Pph3 and
Ptc2 playing overlapping roles, Rad53 dephosphorylation is further delayed in cells lacking both PPH3 and PTC2, with the hyperphosphorylated forms predominating after $6 \mathrm{~h}$ of recovery (Fig. 5B). Notably, reduction in the proportion of the slowest-migrating forms of Rad53 (as opposed to complete dephosphorylation) appears to correlate with replication restart in each of these strains (see below). These results show that a severe defect in Rad53 dephosphorylation accompanies the lethality of ptc2s pph3s cells after MMS treatment.

The severe defect in Rad53 dephosphorylation and le- 
A

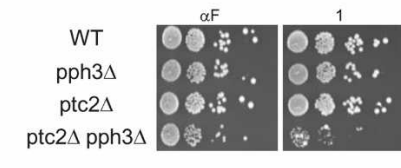

C

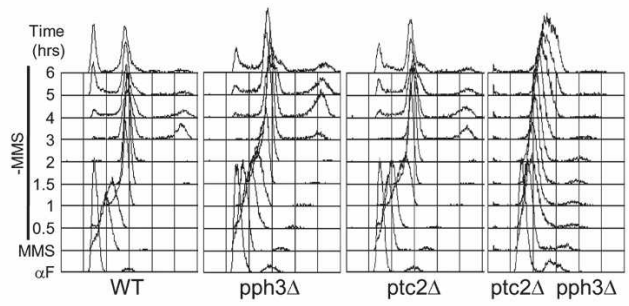

B

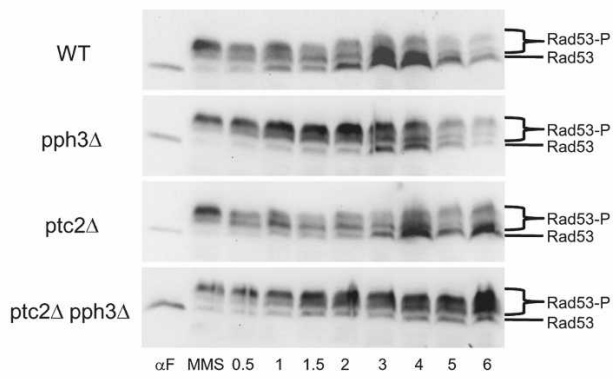

D

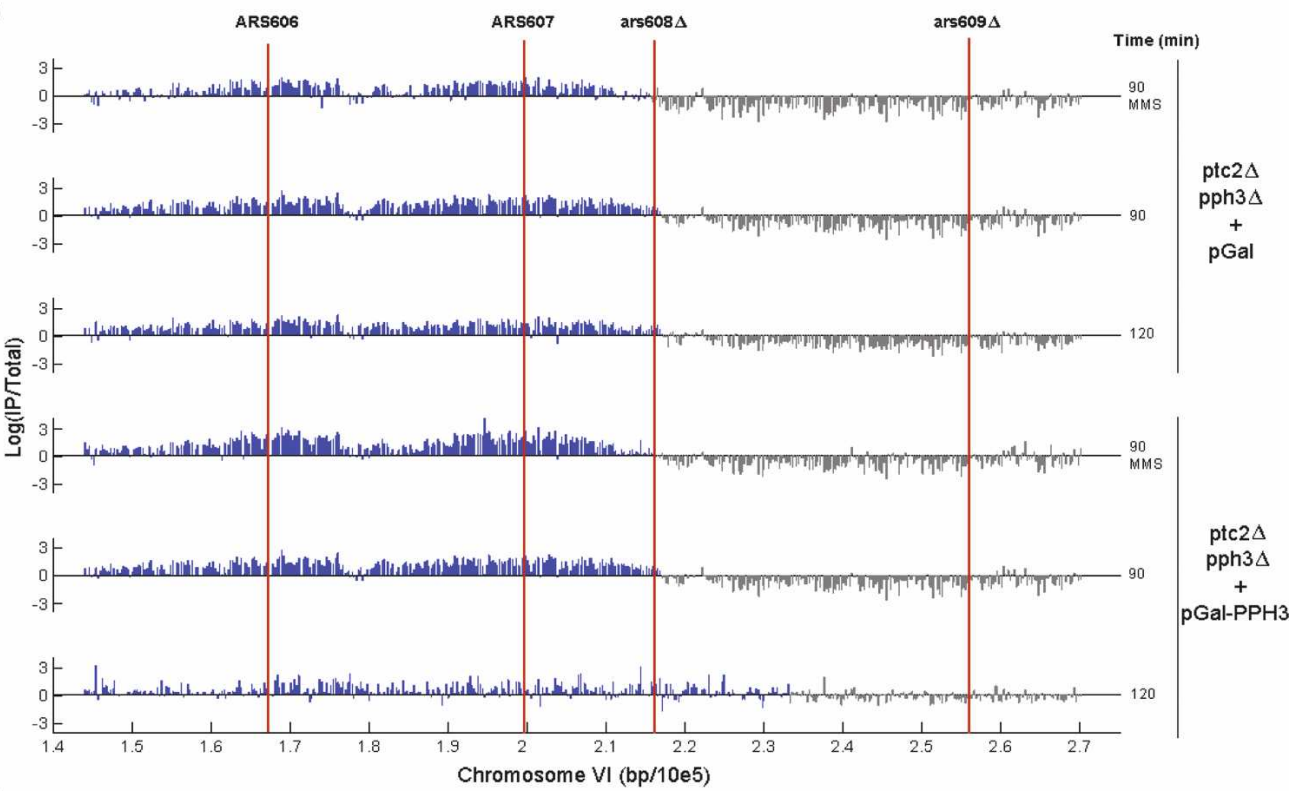

E

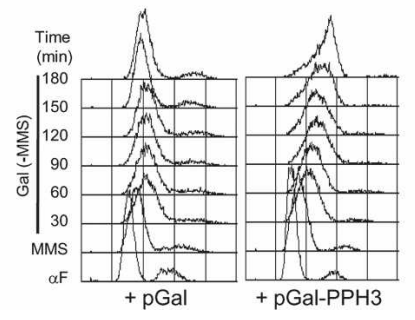

Figure 5. Ptc 2 contributes to viability, dephosphorylation of Rad53, and replication restart in pph3s cells. (A) Wild-type (SSy187), pph3s (SSy188), ptc2s (SSy248), and ptc2s pph3s (SSy249) cells were arrested in G1 phase with $\alpha$-factor at $30^{\circ} \mathrm{C}$ and released into YEPD containing $0.033 \% \mathrm{MMS}$ at $30^{\circ} \mathrm{C}($ Time $=0)$. At the indicated times, cells were 10 -fold serially diluted and plated onto YEPD. Plates were incubated $2 \mathrm{~d}$ at $30^{\circ} \mathrm{C}$ and imaged. $(B, C)$ Strains in $A$ were arrested in G1 phase with $\alpha$-factor at $30^{\circ} \mathrm{C}$ and released into YEPD containing $0.033 \%$ MMS for $45 \mathrm{~min}$ (MMS). MMS was washed out, and cells were suspended in YEPD at $30^{\circ} \mathrm{C}($ Time $=0$ ). Cells were harvested at the indicated time points for immunoblot analysis with anti-Rad53 antibody $(B)$ and DNA content analysis $(C)$. $(D, E)$ ptc2 $\Delta$ pph $3 \Delta$ cells harboring plasmid pGal (SSy526) or pGal-rad53-KD (SSy527) were arrested in G1 phase with $\alpha$-factor at $25^{\circ} \mathrm{C}$ in YEP-Raffinose and released into YEP-Raffinose containing $0.033 \% \mathrm{MMS}$ and BrdU for $90 \mathrm{~min}$ at $23^{\circ} \mathrm{C}$ (MMS). MMS was quenched and washed out and cells were suspended in YEP-Raffinose $+0.5 \%$ galactose containing BrdU (Time $=0)$. Cells were harvested at the indicated times and analyzed for BrdU incorporation $(D)$ and DNA content $(E)$.

thality of DNA-damaged cells deficient in both Pph3 and Ptc2 further supports the conclusion that Rad53 deactivation is required for DNA damage recovery, in particu- lar, the restart of stalled replication forks. This notion predicts that the replication fork restart defect should be exacerbated in $p t c 2 \Delta$ pph $3 \Delta$ cells. We examined total 
DNA content in wild-type, $p p h 3 \Delta, p t c 2 \Delta$, and ptc2 $\Delta$ pph $3 \Delta$ cells during recovery from MMS (Fig. 5C). Wildtype, ptc2s, and pph3 3 cells complete replication after $\sim 1.5,2$, and $3 \mathrm{~h}$ of recovery, respectively. Strikingly, ptc $2 \Delta$ pph $3 \Delta$ cells do not appear to complete replication in this time course, showing limited increase of DNA content during $6 \mathrm{~h}$ of recovery (Fig. 5C). Consistent with this, fork progression completely stalls in ptc2s pph3s cells based on BrdU-IP-chip analysis (Fig. 5D). In fact, we were unable to measure BrdU incorporation in ptc2s pph3s cells during MMS recovery using the pulse-labeling approach, likely because these cells synthesize very little DNA during recovery (Fig. 5C). Thus, we used a cumulative labeling approach with BrdU present throughout the time course, including S-phase entry in the presence of MMS and during recovery from the MMS (Fig. 5D). In ptc2s pph3s cells exposed to MMS, BrdU incorporation ceases $\sim 15-20 \mathrm{~kb}$ from ARS607, and very little further incorporation is observed during $2 \mathrm{~h}$ of recovery. Restoration of Pph3 activity in these cells by induction of GAL-PPH3 during recovery permits resumption of DNA synthesis from the stalled forks (Fig. 5D) and completion of bulk DNA synthesis (Fig. 5E). Analysis of the chromosome III replicon shows similar results (Supplemental Fig. S4). The failure of ptc2s pph $3 \Delta$ cells to restart replication provides a compelling cause for the lethality of these cells after exposure to MMS. Furthermore, the synergistic effect of loss of two different Rad53 phosphatases on replication fork restart directly supports the notion that Rad53 deactivation is a key step in this process.

To verify that failure of Rad53 deactivation causes the failed replication restart and lethality of ptc2s pph3s cells, we induced expression of Rad53-KD in wild-type, pph $3 \Delta$, ptc2s, and ptc2s pph $3 \Delta$ cells beginning recovery from MMS-induced DNA damage (Fig. 6A). Expression of Rad53-KD has little effect on kinetics of DNA replication during recovery of wild-type and ptc2s cells. As shown above (Fig. 4A), expression of Rad53-KD largely eliminates the delay in replication restart of pph3s cells (Fig. 6A). Consistent with a direct link between defective Rad53 dephosphorylation and replication restart, expression of Rad53-KD enables replication restart in ptc2s pph3s cells, with these cells largely completing replication by $4 \mathrm{~h}$. The longer time (compared with pph $3 \Delta$ cells) required for replication restart in $p t c 2 \Delta p p h 3 \Delta$ cells probably reflects the lack of Ptc2 activity contributing to Rad53 deactivation by Rad53-KD. Indeed, we confirmed that overexpression of Rad53-KD suppressed the endogenous Rad53-associated kinase activity in ptc2 $\Delta$ pph3s cells (Fig. 6B); however, the rate of Rad53 deactivation was lower than in pph3s cells (Fig. 4B), consistent with Ptc2 contributing to Rad53 deactivation by Rad53-KD. Finally, expression of Rad53-KD partially rescues the viability of MMS-treated ptc2s pph3s cells (Fig. 6C), which is fully consistent with the conclusion that Rad53

A

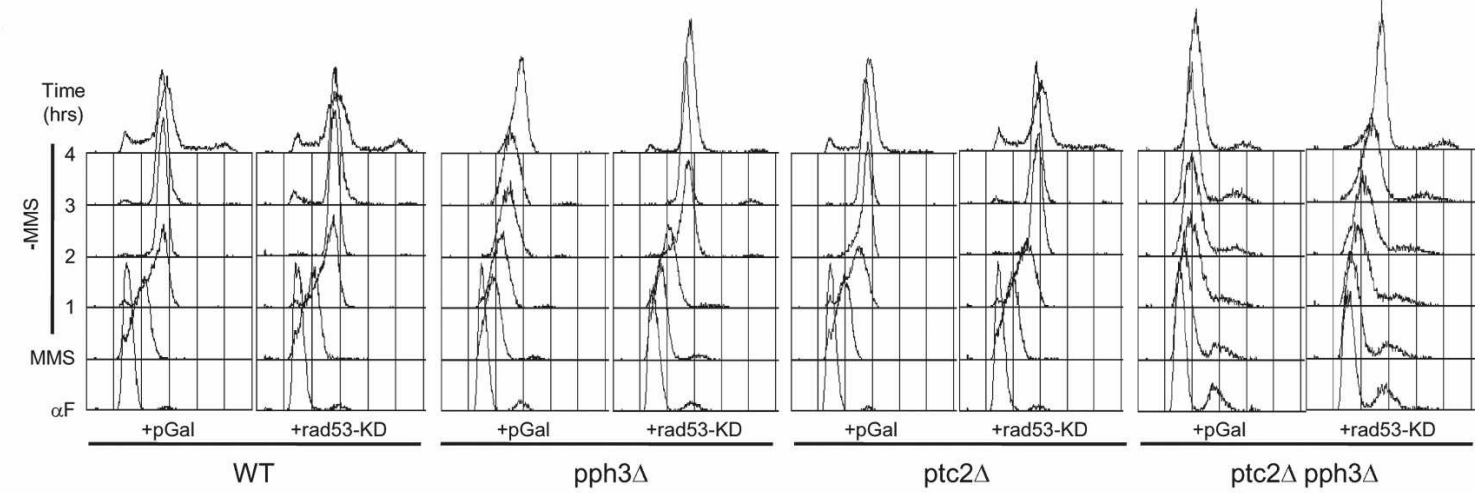

B

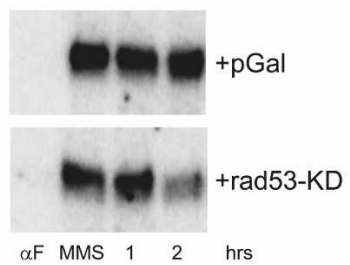

C

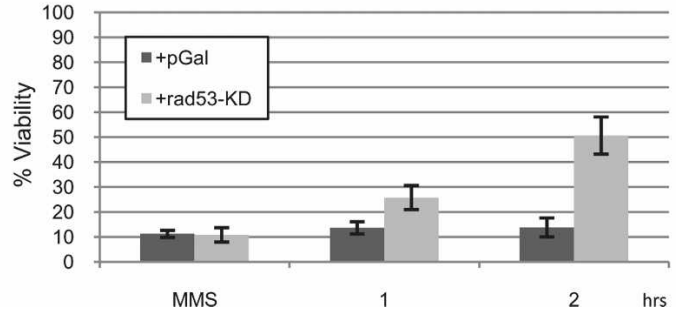

Figure 6. Antagonism of Rad53 activity restores replication and viability of pph3s ptc2 $\Delta$ cells. Wild-type + pGal (SSy385), + rad53-KD

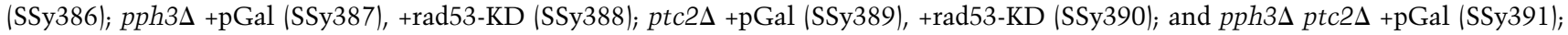
$+\operatorname{rad} 53-\mathrm{KD}$ (SSy392) cells were blocked in G1 phase with $\alpha$-factor in YEP-Raffinose and released into YEP-Raffinose containing 0.033\% MMS for $90 \mathrm{~min}$ at $23^{\circ} \mathrm{C}$ (MMS). MMS was washed out and cells were suspended in YEP-Raffinose $+0.5 \%$ Galactose $($ Time $=0)$. $(A)$ DNA content was analyzed at the indicated times. (B) In situ Rad53 kinase assay of SSy391 and SSy392. (C) Percent viability of SSy391 and SSy392 was determined relative to the $\alpha$-factor time point; standard error for three independent experiments is shown. 
deactivation is necessary and sufficient to restart replication forks stalled by DNA damage, and thereby avert lethality.

\section{Discussion}

\section{Activated Rad53 regulates replication fork restart}

Rad53 plays a crucial role in the stabilization of replication forks encountering DNA damage. The mechanism of stabilization remains vague, but is thought to involve Rad53-dependent phosphorylation of replication proteins to maintain their association with the fork and thereby prevent fork collapse and formation of dsDNA breaks, which occurs in the absence of Rad53 (Branzei and Foiani 2006). We exploited the defect of $p p h 3 \Delta$ cells in deactivating Rad53 to examine replication fork activity under constant Rad53 control. The slower replication fork progression in MMS-damaged pph3s cells strongly suggests that activated Rad53 directly impedes fork restart or restart by phosphorylating replication factors. We further showed that deactivation of Rad53 is sufficient to allow replication fork restart in cells recovering from DNA damage. This finding links replication restart with dephosphorylation and deactivation of Rad53, which normally results from diminution of the checkpoint signal as DNA damage is repaired. By inhibiting replication fork restart as well as additional origin firing, Rad53 provides a better opportunity for repair of damaged DNA prior to arrival of a replication fork.

Our conclusion that Rad53 directly regulates fork activity contrasts with the conclusion of Tercero and Diffley (2001), who observed similarly slow replication fork kinetics across the chromosome VI replicon in wild-type and rad53 3 cells in the presence of MMS, leading them to conclude that while DNA damage slows replication fork progression, Rad53 does not regulate the rate of fork progression in response to DNA damage. Using BrdU-IPchip, we also find that fork rates are similar in wild-type and rad53s cells (Supplemental Fig. S5). Based on our conclusion that deactivation of Rad53 is required for fork restart, a seemingly straightforward prediction is that rad53 $\Delta$ cells would exhibit more rapid fork progression in the presence of MMS than wild-type cells, which is not observed. However, elimination of Rad53 complicates the situation by the resulting failure to stabilize stalled forks. Thus, we suggest (in agreement with Tercero and Diffley 2001) that DNA damage intrinsically slows or stalls fork progression independently of Rad53, perhaps by provoking uncoupling of the fork from the damaged site and generating a DNA damage signal (see below). Subsequent fork stabilization by Rad53 ensures that stalled forks are channeled into an efficient, direct restart pathway, but only upon deactivation of Rad53. In the case of rad53 $\Delta$ cells, the initial failure to stabilize the correct fork structure may preclude rapid and direct restart by the preferred pathway(s) and rely instead on alternative restart mechanisms. Indeed, fork collapse stimulates repair by homologous recombination, which is normally suppressed by Rad53 (for review, see Lam- bert et al. 2007). Ultimately, although fork progression through the chromosome VI region occurs with approximately wild-type kinetics in MMS-treated rad53s cells, unreplicated DNA remains, and these cells are inviable (Tercero and Diffley 2001). In contrast, pph3s cells maintain stable replication forks in the presence of DNA damage and remain viable (Fig. 5A; O'Neill et al. 2007).

\section{A model of Rad53 regulation of replication fork restart}

Current models for replication of a damaged template invoke uncoupling of leading and lagging strand synthesis when leading strand synthesis is blocked by a lesion, while a block of the lagging strand is normally uncoupled as an Okazaki fragment and does not block fork progression (for review, see Heller and Marians 2006). Uncoupling allows continued template unwinding and lagging strand DNA synthesis that enables replication restart beyond the blocking lesion through a repriming event on the leading strand template. As a result of uncoupling from the blocking lesions and downstream repriming of DNA synthesis, unreplicated gaps are left behind the fork, presumably generating a DNA damage signal. These gaps can be repaired by one of several postreplication repair (PRR) mechanisms, including recruitment of translesion polymerase(s), template switching, and homologous recombination (Ulrich 2005). However, some restart mechanisms, such as fork regression by Rad5 and translesion synthesis (TLS), may act directly in fork restart without a repriming mechanism, which remains speculative in eukaryotes. How the repair pathway is chosen remains unclear, but likely depends on the nature of the lesion and whether Rad53 stabilizes the uncoupled fork.

Rad53 may limit progression of the uncoupled fork by inhibiting helicase activity or lagging strand synthesis to prevent the formation of long unreplicated gaps (Fig. 7). By limiting the extent of lagging strand synthesis, Rad53 may facilitate Rad5-dependent fork regression as a restart mechanism, which may not act over very long distances in vivo; although Rad5 can regress fork-like structures $\sim 1 \mathrm{~kb}$ in vitro (Blastyak et al. 2007), its activity may be constrained to lesions near the fork in vivo. The Rad5 mechanism is error-free and bypasses the blocking lesion without producing gaps in the DNA. Hence, it is interesting that MMS does not appear to provoke the same level of gap formation, suggestive of fork uncoupling, as UV treatment (Sogo et al. 2002), raising the possibility that Rad53 inhibits fork uncoupling in MMS, thereby facilitating direct restart of stalled forks by Rad5. Different mechanisms may act depending on the level of Rad53 activity in the cell when the fork encounters the lesion. For example, early in S phase before Rad53 has been activated, extensive fork progression after uncoupling may occur, requiring repriming and gap repair, whereas later in S phase after Rad53 has become fully active, fork progression may be rapidly halted after uncoupling, or uncoupling may be prevented to enable Rad5-dependent restart.

Fork uncoupling may intrinsically regulate the rate of 


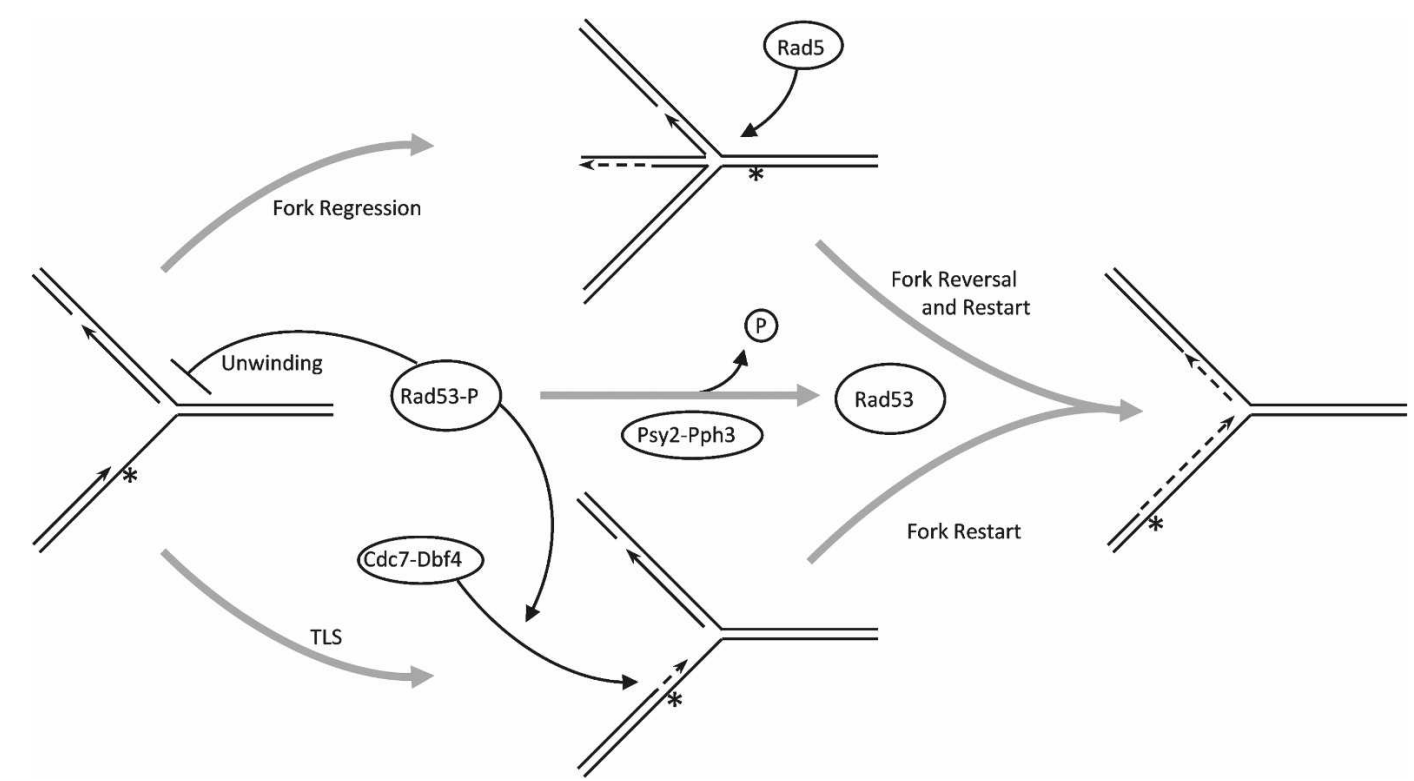

Figure 7. A model of Rad53 regulation of replication fork restart. Arrows on the DNA structures represent $3^{\prime}$ ends, the asterisks represent a fork-blocking lesion, and dashed lines indicate new DNA synthesis. Thin curved lines represent protein function, ending with arrows for activation or perpendicular lines for inhibition. See the Discussion for additional details.

fork progression by modulating helicase activity. Helicase rate and processivity are stimulated by coupled polymerase activity (Dong et al. 1996; Kim et al. 1996; Yuzhakov et al. 1996; Stano et al. 2005; Hamdan et al. 2007). Thus, uncoupling of a blocked leading strand polymerase may enable a limited amount of continued unwinding and lagging strand synthesis, which facilitates restart, while preventing excessive formation of unreplicated gaps in the DNA. It is unclear whether Rad53 regulates fork coupling; however, Mrc1, a Rad53-activating protein that functions at replication forks appears to regulate this process, as delocalization of the replication apparatus from the site of stalled DNA synthesis occurs in HU-treated mrc1s cells (Katou et al. 2003). Interestingly, cells lacking Mrcl exhibit significantly slower fork progression in the absence of DNA damage, consistent with the notion that fork uncoupling slows fork progression (Szyjka et al. 2005; Tourriere et al. 2005; Hodgson et al. 2007). Mrcl appears to be phosphorylated by activated Rad53 (Osborn and Elledge 2003), which may prevent uncoupling to limit ongoing replication of a heavily damaged template while providing an opportunity for repair.

The regulation of Cdc7-Dbf4 also may be a key feature of Rad53 regulation of replication restart (Fig. 7). Rad53dependent inhibition of late origin firing is thought to occur through phosphorylation of Dbf4, resulting in reduced Cdc7 kinase activity and dissociation from chromatin (Weinreich and Stillman 1999; Duncker et al. 2002). However, recent studies in human cancer cells suggest Cdc7 kinase is active under replication stress conditions (Tenca et al. 2007). A possible explanation for this apparent discrepancy is that Rad53 may inhibit Cdc7-Dbf4 activity in normal replication initiation at origins while stimulating Cdc7-Dbf4 activity in replica- tion fork restart. Consistent with this idea, Cdc7-Dbf4 has been implicated in error-prone TLS. Cdc7 is required for induced mutagenesis by UV and MMS, and combined mutations of CDC7 and RAD5 cause synergistic increases in UV and MMS sensitivities (Njagi and Kilbey 1982; Pessoa-Brandao and Sclafani 2004). This indicates that Rad5 and Cdc7-Dbf4-dependent TLS function in parallel and suggests that Rad53 may regulate this choice (Fig. 7). In Schizosaccharomyces pombe, mutations in hsk1 or dfp1 (CDC7 and DBF4 homologs, respectively) cause MMS sensitivity and chromosomal instability, consistent with a role in replication fork stabilization or restart, and Cds1 (RAD53 homolog) appears to directly target Hsk1-Dfp1 for regulation (Takeda et al. 1999, 2001; Snaith et al. 2000; Fung et al. 2002; Matsumoto et al. 2005; Sommariva et al. 2005). Consistent with the idea that Cds1 controls the choice of replication restart pathways is the finding that $c d s 1$ deletion exacerbates induced mutagenesis resulting from a defective allele of DNA Polymerase $\alpha$, which likely causes frequent fork stalling (Kai and Wang 2003). Together, these findings suggest that Cdc7-Dbf4 is required for replication restart through the TLS pathway and that Rad53 modulates this activity.

Distinct and overlapping roles of Rad53 phosphatases in checkpoint regulation

In constant MMS, replication forks progress more slowly in pph3s cells than in wild-type cells (Fig. 1A; Supplemental Fig. S1), implying that Pph3 dephosphorylation of Rad53 constitutively opposes Rad53 activation. Thus, the slow but continuous fork progression in wild-type cells (in MMS) likely reflects a cycle of fork stabilization by Rad53 and fork restart through Rad53 dephosphory- 
lation. Complete Rad53 dephosphorylation may not be required if specific hyperphosphorylated form(s) inhibit restart or if a graded response to the level of Rad53 phosphorylation occurs. The data support this idea, as replication restart appears to correlate with reduction in the level of the slowest migrating forms of Rad53 (Fig. 5B,C). An attractive possibility for regulation of Pph3 activity may be through its targeting to replication forks (perhaps by Psy2) to dephosphorylate Rad53 only when these forks are prepared for restart, for example, after lesion bypass by Rad5.

The progression of replication forks in MMS-treated pph $3 \Delta$ cells slows but does not arrest completely (Fig. 1A; Supplemental Fig. S1), indicating either that activated Rad53 does not completely block fork progression or restart or that an alternative means of Rad53 deactivation occurs in $p p h 3 \Delta$ cells. Consistent with the latter hypothesis, reduced levels of phosphorylated Rad53 eventually are observed in pph $3 \Delta$ cells (Fig. 5B). We tested the involvement of PTC2, which encodes a Rad53 phosphatase previously characterized as having a role in recovery from cell cycle arrest caused by a long-lived, dsDNA break (Leroy et al. 2003). We found that combined disruption of Pph3 and Ptc2 activity virtually eliminates replication fork restart and causes lethality after MMS-induced damage, reinforcing the conclusion that Rad53 deactivation is the key function of Pph3 in replication restart. Furthermore, we showed that direct antagonism of activated Rad53 by overexpression of Rad53-KD enables replication restart and rescues the lethality of $p p h 3 \Delta p t c 2 \Delta$ cells, which are otherwise unable to deactivate Rad53. Based on these results, we conclude that Rad53 deactivation is necessary for replication fork restart after damage-induced stalling and Rad53-dependent fork stabilization.

Pph3 and Ptc2 appear to play differential roles in Rad53 deactivation depending on the source of checkpoint activation. We find only a minor requirement for Ptc2 in dephosphorylation of Rad53 and replication restart during recovery from MMS, except in cells lacking Pph3 (Figs. 5, 6). Ptc2 and Pph3 interact with different domains of Rad53 and, therefore, may preferentially dephosphorylate distinct phospho-sites (Leroy et al. 2003; $\mathrm{O}^{\prime}$ Neill et al. 2007). Specific phospho-sites may regulate distinct aspects of Rad53 function, so the ability to deactivate specific sites with a unique phosphatase potentially allows for modulation of the checkpoint response for the specific circumstances (for review, see Heideker et al. 2007). Along these lines, Pph3 may prefer Rad53 phospho-sites that regulate replication fork restart after MMS damage, while Ptc2 may favor sites that regulate G2 arrest and adaptation after dsDNA break (Fig. 5B; Leroy et al. 2003; O'Neill et al. 2007). Furthermore, neither Pph3, nor Ptc2, nor Ptc3, alone or in combination, is required for viability after $\mathrm{HU}$ treatment, suggesting that Rad53 phospho-sites may be differentially targeted in response to different types of replication stress (Supplemental Fig. S4). Similar findings were reported while this paper was in revision (Travesa et al. 2008). Obviously, determining the Rad53 phospho-site specificities of Pph3 and Ptc2 will be highly illuminating. Little is known about the regulation of these phosphatases in DNA damage responses, knowledge of which will also be crucial to understanding fully checkpoint recovery.

\section{Conclusions}

Replication forks stall at sites of DNA damage resulting in Rad53 activation, which stabilizes the stalled forks to prevent their collapse. The restart of DNA synthesis at replication forks is coupled to $\operatorname{Rad} 53$ deactivation through dephosphorylation. Modulation of replication fork restart (and late origin firing) provides time for repair of DNA damage, which may reduce the frequency of fork stalling events, and risk of genomic instability. Rad53's action at the fork may also direct the choice of replication restart mechanism, perhaps favoring direct fork restart pathways. Recent studies in human cells using DNA fiber analyses have yielded conflicting results on the effects of intra-S checkpoint control on replication forks (Merrick et al. 2004; Seiler et al. 2007; UnsalKacmaz et al. 2007). As DNA replication, DNA repair, and the related surveillance mechanisms are highly conserved among eukaryotes, our findings should provide direct insights into these vital processes in human cells.

\section{Materials and methods}

\section{Plasmid and strain constructions}

Strains are described in Supplemental Table 1. Gene knockouts were constructed by PCR-based methods (Guldener et al. 1996; Longtine et al. 1998). To construct pGal-rad53-KD, the 1.6-kb BstEII-SphI fragment of RAD53 (SPK1) containing the kinaseinactivating mutations $\mathrm{K} 227 \mathrm{~A}$ and D339A was isolated from pRS316-SPK1-(K227A,D339A) (Fay et al. 1997) and subcloned into BstEII-SphI-digested pJA98 (Allen et al. 1994). To construct pGal-PPH3, genomic DNA from SSy250 was amplified with a primer (containing an SphI site) upstream of the GAL promoter and a primer just downstream from an endogenous MscI site within the PPH3 gene. The PCR product was digested with SphI and MscI and ligated into pFR071 (YEplac195-PPH3; O'Neill et al. 2007).

\section{Yeast methods}

YEPD medium was used for all experiments, except where noted. Raffinose was present at $2 \%$ in YEP-Raffinose. Cell culturing, synchronization, DNA content analysis (FACScan), and Rad53 analysis have been described (Aparicio et al. 2004; Gibson et al. 2004), except we used anti-Rad53 antibody at 1:1000 (Santa Cruz Biotechnology, SC6749). The in situ Rad53 kinase assay is described in Pellicioli et al. (1999). For DNA damage recovery experiments, MMS (Sigma) was quenched by addition of sodium thiosulfate to $0.5 \%$; cells were immediately harvested by centrifugation and resuspended as indicated in the figure legends. Budding index was determined by counting 200 cells per time point.

\section{Viability analysis}

Approximately $7.5 \times 10^{6}$ cells were removed from culture, sonicated, 10-fold serially diluted, plated onto YEPD, and incubated 
for $2 \mathrm{~d}$ at $30^{\circ} \mathrm{C}$. Plates were imaged using a ChemiDoc XRS 170-8070 (Bio-Rad) and Quantity One Analysis software (BioRad). Quantification of viability was performed by duplicate platings onto YEPD of appropriate culture dilutions that result in 100-200 colonies per plate.

\section{BrdU-IP-chip}

Strains containing the BrdU-Inc construct (Viggiani and Aparicio 2006) were incubated with $800 \mu \mathrm{g} / \mathrm{mL} \mathrm{BrdU}$ (Sigma) and harvested with the addition of ice-cold TBS and $0.1 \% \mathrm{NaN}_{3}$. DNA isolation and BrdU immunoprecipitation were performed as previously described (Szyjka et al. 2005), except that antiBrdU (GE Healthcare) was used at 1:400 and incubated overnight at $4{ }^{\circ} \mathrm{C}$. To obtain a reference "total DNA" sample, DNA was isolated from a G1-arrested culture. Amplification of immunoprecipitated and total DNA was performed as described $\left(\mathrm{O}^{\prime}\right.$ Geen et al. 2006), except that amplified samples were subjected to Klenow extension for $4 \mathrm{~h}$ at $37^{\circ} \mathrm{C}$ in the presence of aminoallyl-dUTP (48 $\mu \mathrm{M}$, Ambion) and dNTPs (dATP, dGTP, dCTP: $120 \mu \mathrm{M}$; dTTP: $72 \mu \mathrm{M}$ ). Also spiked into each amplification reaction was $0.5 \mu \mathrm{L}$ of 10 Drosophila cDNA clones (corresponding to Drosophila oligonucleotides on the mircoarrays, see below) that span a 100 -fold concentration range (1-100 pg/ $\mu \mathrm{L}$ ), which produce a range of signal intensities for data normalization. Immunoprecipitated and total DNA samples were coupled with Cy5 or Cy3 dyes (GE Healthcare) for $1 \mathrm{~h}$ at room temperature, respectively. After purifying DNA samples using Qiaquick spin columns (Qiagen), $1 \mu \mathrm{g}$ of total DNA and $1 \mu \mathrm{g}$ of each immunoprecipitated sample were combined, dried in a SpeedVac (Thermo), resuspended in $10 \mathrm{mM}$ EDTA, and denatured for $2 \mathrm{~min}$. Prewarmed $\left(50^{\circ} \mathrm{C}\right)$ hybridization buffer $(30 \%$ formamide, $5 \times$ SSC, $0.1 \%$ SDS, $100 \mu \mathrm{g} / \mathrm{mL}$ salmon sperm DNA) was added to denatured samples and hybridized to prewarmed microarrays for $18 \mathrm{~h}$ at $50^{\circ} \mathrm{C}$; one slide was used for each experimental time point. Slides were washed with gentle shaking in $1 \times \mathrm{SSC}, 0.1 \%$ SDS, $1 \mathrm{mM}$ DTT (prewarmed to $50^{\circ} \mathrm{C}$ ) for 5 min, submerged several times in $0.2 \times \mathrm{SSC}, 1 \mathrm{mM} \mathrm{DTT}\left(23^{\circ} \mathrm{C}\right)$, and washed two times for $3 \mathrm{~min}$ in $0.1 \times \mathrm{SSC}, 1 \mathrm{mM} \mathrm{DTT}\left(23^{\circ} \mathrm{C}\right)$. Slides were dried by centrifugation for $45 \mathrm{sec}$ in a microcentrifuge and scanned in an Axon scanner using Genepix 5.0 to capture and save the images.

\section{Microarray design and production}

Oligonucleotide probes $\left(60 \mathrm{bp}, T_{\mathrm{m}}\right.$ range $\left.=80-90^{\circ} \mathrm{C}\right)$ were designed to analyze chromosome VI (coordinates: 143,000270,000; one probe per $270 \mathrm{bp}$ ) and part of the left arm of chromosome III (coordinates: 11,300-77,700; one probe per $100 \mathrm{bp}$ ) using OligoArray 2.1 (Rouillard et al. 2003). Fifty oligonucleotides (five unique oligonucleotides for each of the 10 Drosophila cDNA clones described above) were similarly designed to detect the spiked-in Drosophila cDNAs for data normalization. Oligonucleotides were printed in quadruplicate on poly-lysine slides (Erie Scientific) using either a MicroGrid I BioRobotics or MGuide printer (http://cmgm.stanford.edu/pbrown/mguide). Post-processing utilized succinic anhydride as blocking reagent, as described at http://cmgm.stanford.edu/pbrown/protocols/ 3_post_process.html.

\section{Microarray analysis}

ImaGene image analysis software (http://www.biodiscovery. com/index/imagene) was used to quantify raw spot intensities, and low-level analysis of the arrays was performed using LIMMA software (Smyth 2004), available from Bioconductor and R (R Development Core Team 2007). Local background correction was applied, and normalization was performed using the Drosophila spike-in probes on the arrays. Further details may be found in the Supplemental Material.

\section{Acknowledgments}

For invaluable advice and/or assistance with production of DNA microarrays, we are grateful to Michelle Arbeitman, Judy Campbell, Maxine Chaney, Andrew Gracey, and especially Jose-Luis Reichmann (CalTech Microarray Core). We also thank Susan Forsburg for critical reading of the manuscript; Michelle Arbeitman, Norman Arnheim, and Myron Goodman for sharing equipment; and Michelle Arbeitman, Jeff Bachant, Floyd Romesberg, and David Stern for providing plasmids. This work was supported by NIH grants RO1-GM65494 (to O.M.A.) and RO1-GM67243 (to S.T.) and aided by grant IRG-58-007-42 from the American Cancer Society.

\section{References}

Allen, J.B., Zhou, Z., Siede, W., Friedberg, E.C., and Elledge, S.J. 1994. The SAD1/RAD53 protein kinase controls multiple checkpoints and DNA damage-induced transcription in yeast. Genes \& Dev. 8: 2401-2415.

Aparicio, J.G., Viggiani, C.J., Gibson, D.G., and Aparicio, O.M. 2004. The Rpd3-Sin3 histone deacetylase regulates replication timing and enables intra-S origin control in Saccharomyces cerevisiae. Mol. Cell. Biol. 24: 4769-4780.

Blastyak, A., Pinter, L., Unk, I., Prakash, L., Prakash, S., and Haracska, L. 2007. Yeast Rad5 protein required for postreplication repair has a DNA helicase activity specific for replication fork regression. Mol. Cell 28: 167-175.

Branzei, D. and Foiani, M. 2006. The Rad53 signal transduction pathway: Replication fork stabilization, DNA repair, and adaptation. Exp. Cell Res. 312: 2654-2659.

Desany, B.A., Alcasabas, A.A., Bachant, J.B., and Elledge, S.J. 1998. Recovery from DNA replicational stress is the essential function of the S-phase checkpoint pathway. Genes \& Dev. 12: 2956-2970.

Dong, F., Weitzel, S.E., and von Hippel, P.H. 1996. A coupled complex of T4 DNA replication helicase (gp41) and polymerase (gp43) can perform rapid and processive DNA stranddisplacement synthesis. Proc. Natl. Acad. Sci. 93: 1445614461.

Duncker, B.P., Shimada, K., Tsai-Pflugfelder, M., Pasero, P., and Gasser, S.M. 2002. An N-terminal domain of Dbf4p mediates interaction with both origin recognition complex (ORC) and Rad53p and can deregulate late origin firing. Proc. Natl. Acad. Sci. 99: 16087-16092.

Fay, D.S., Sun, Z., and Stern, D.F. 1997. Mutations in SPK1/ RAD53 that specifically abolish checkpoint but not growthrelated functions. Curr. Genet. 31: 97-105.

Fung, A.D., Ou, J., Bueler, S., and Brown, G.W. 2002. A conserved domain of Schizosaccharomyces pombe $\operatorname{dfp} 1(+)$ is uniquely required for chromosome stability following alkylation damage during S phase. Mol. Cell. Biol. 22: 44774490.

Gibson, D.G., Aparicio, J.G., Hu, F., and Aparicio, O.M. 2004. Diminished S-phase cyclin-dependent kinase function elicits vital Rad53-dependent checkpoint responses in Saccharomyces cerevisiae. Mol. Cell. Biol. 24: 10208-10222.

Guldener, U., Heck, S., Fielder, T., Beinhauer, J., and Hegemann, J.H. 1996. A new efficient gene disruption cassette for 
repeated use in budding yeast. Nucleic Acids Res. 24: 25192524.

Hamdan, S.M., Johnson, D.E., Tanner, N.A., Lee, J.B., Qimron, U., Tabor, S., van Oijen, A.M., and Richardson, C.C. 2007. Dynamic DNA helicase-DNA polymerase interactions assure processive replication fork movement. Mol. Cell 27: 539-549.

Heideker, J., Lis, E.T., and Romesberg, F.E. 2007. Phosphatases, DNA damage checkpoints and checkpoint deactivation. Cell Cycle 6: $3058-3064$.

Heller, R.C. and Marians, K.J. 2006. Replisome assembly and the direct restart of stalled replication forks. Nat. Rev. Mol. Cell Biol. 7: 932-943.

Hodgson, B., Calzada, A., and Labib, K. 2007. Mrc1 and Tof1 regulate DNA replication forks in different ways during normal S phase. Mol. Biol. Cell 18: 3894-3902.

Kai, M. and Wang, T.S. 2003. Checkpoint activation regulates mutagenic translesion synthesis. Genes \& Dev. 17: 64-76.

Katou, Y., Kanoh, Y., Bando, M., Noguchi, H., Tanaka, H., Ashikari, T., Sugimoto, K., and Shirahige, K. 2003. S-phase checkpoint proteins Tof1 and Mrc1 form a stable replication-pausing complex. Nature 424: 1078-1083.

Keogh, M.C., Kim, J.A., Downey, M., Fillingham, J., Chowdhury, D., Harrison, J.C., Onishi, M., Datta, N., Galicia, S., Emili, A., et al. 2006. A phosphatase complex that dephosphorylates $\gamma \mathrm{H} 2 \mathrm{AX}$ regulates DNA damage checkpoint recovery. Nature 439: 497-501.

Kim, S., Dallmann, H.G., McHenry, C.S., and Marians, K.J. 1996. Coupling of a replicative polymerase and helicase: A $\tau-$ DnaB interaction mediates rapid replication fork movement. Cell 84: 643-650.

Kolodner, R.D., Putnam, C.D., and Myung, K. 2002. Maintenance of genome stability in Saccharomyces cerevisiae. Science 297: 552-557.

Labib, K., Tercero, J.A., and Diffley, J.F. 2000. Uninterrupted MCM2-7 function required for DNA replication fork progression. Science 288: 1643-1647.

Lambert, S., Froget, B., and Carr, A.M. 2007. Arrested replication fork processing: Interplay between checkpoints and recombination. DNA Repair (Amst.) 6: 1042-1061.

Leroy, C., Lee, S.E., Vaze, M.B., Ochsenbien, F., Guerois, R., Haber, J.E., and Marsolier-Kergoat, M.C. 2003. PP2C phosphatases Ptc2 and Ptc3 are required for DNA checkpoint inactivation after a double-strand break. Mol. Cell 11: 827835.

Longtine, M.S., McKenzie 3rd, A., Demarini, D.J., Shah, N.G., Wach, A., Brachat, A., Philippsen, P., and Pringle, J.R. 1998. Additional modules for versatile and economical PCR-based gene deletion and modification in Saccharomyces cerevisiae. Yeast 14: 953-961.

Lopes, M., Cotta-Ramusino, C., Pellicioli, A., Liberi, G., Plevani, P., Muzi-Falconi, M., Newlon, C.S., and Foiani, M. 2001. The DNA replication checkpoint response stabilizes stalled replication forks. Nature 412: 557-561.

Matsumoto, S., Ogino, K., Noguchi, E., Russell, P., and Masai, H. 2005. Hsk1-Dfp1/Him1, the Cdc7-Dbf4 kinase in Schizosaccharomyces pombe, associates with Swil, a component of the replication fork protection complex. J. Biol. Chem. 280: 42536-42542.

Melo, J. and Toczyski, D. 2002. A unified view of the DNAdamage checkpoint. Curr. Opin. Cell Biol. 14: 237-245.

Merrick, C.J., Jackson, D., and Diffley, J.F. 2004. Visualization of altered replication dynamics after DNA damage in human cells. J. Biol. Chem. 279: 20067-20075.

Njagi, G.D. and Kilbey, B.J. 1982. cdc7-1 a temperature sensitive cell-cycle mutant which interferes with induced mutagen- esis in Saccharomyces cerevisiae. Mol. Gen. Genet. 186: 478-481.

O'Geen, H., Nicolet, C.M., Blahnik, K., Green, R., and Farnham, P.J. 2006. Comparison of sample preparation methods for ChIP-chip assays. Biotechniques 41: 577-580.

O’Neill, B.M., Szyjka, S.J., Lis, E.T., Bailey, A.O., Yates 3rd, J.R., Aparicio, O.M., and Romesberg, F.E. 2007. Pph3-Psy2 is a phosphatase complex required for Rad53 dephosphorylation and replication fork restart during recovery from DNA damage. Proc. Natl. Acad. Sci. 104: 9290-9295.

Osborn, A.J. and Elledge, S.J. 2003. Mrc1 is a replication fork component whose phosphorylation in response to DNA replication stress activates Rad53. Genes \& Dev. 17: 17551767.

Paciotti, V., Clerici, M., Scotti, M., Lucchini, G., and Longhese, M.P. 2001. Characterization of mecl kinase-deficient mutants and of new hypomorphic mecl alleles impairing subsets of the DNA damage response pathway. Mol. Cell. Biol. 21: 3913-3925.

Painter, R.B. and Young, B.R. 1980. Radiosensitivity in ataxiatelangiectasia: A new explanation. Proc. Natl. Acad. Sci. 77: 7315-7317.

Paulovich, A.G. and Hartwell, L.H. 1995. A checkpoint regulates the rate of progression through $\mathrm{S}$ phase in $\mathrm{S}$. cerevisiae in response to DNA damage. Cell 82: 841-847.

Paulovich, A.G., Margulies, R.U., Garvik, B.M., and Hartwell, L.H. 1997. RAD9, RAD17, and RAD24 are required for S phase regulation in Saccharomyces cerevisiae in response to DNA damage. Genetics 145: 45-62.

Paulsen, R.D. and Cimprich, K.A. 2007. The ATR pathway: Fine-tuning the fork. DNA Repair (Amst.) 6: 953-966.

Pellicioli, A., Lucca, C., Liberi, G., Marini, F., Lopes, M., Plevani, P., Romano, A., Di Fiore, P.P., and Foiani, M. 1999. Activation of Rad53 kinase in response to DNA damage and its effect in modulating phosphorylation of the lagging strand DNA polymerase. EMBO J. 18: 6561-6572.

Pessoa-Brandao, L. and Sclafani, R.A. 2004. CDC7/DBF4 functions in the translesion synthesis branch of the RAD6 epistasis group in Saccharomyces cerevisiae. Genetics 167: 1597-1610.

R Development Core Team. 2007. R: A language and environment for statistical computing. R Foundation for Statistical Computing, Vienna, Austria.

Rouillard, J.M., Zuker, M., and Gulari, E. 2003. OligoArray 2.0: Design of oligonucleotide probes for DNA microarrays using a thermodynamic approach. Nucleic Acids Res. 31: 30573062.

Seiler, J.A., Conti, C., Syed, A., Aladjem, M.I., and Pommier, Y. 2007. The intra-S-phase checkpoint affects both DNA replication initiation and elongation: Single-cell and -DNA fiber analyses. Mol. Cell. Biol. 27: 5806-5818.

Shimada, K., Pasero, P., and Gasser, S.M. 2002. ORC and the intra-S-phase checkpoint: A threshold regulates Rad53p activation in S phase. Genes \& Dev. 16: 3236-3252.

Smyth, G.K. 2004. Linear models and empirical bayes methods for assessing differential expression in microarray experiments. Stat. Appl. Genet. Mol. Biol. 3: Article 3.

Snaith, H.A., Brown, G.W., and Forsburg, S.L. 2000. Schizosaccharomyces pombe Hsklp is a potential cdslp target required for genome integrity. Mol. Cell. Biol. 20: 7922-7932.

Sogo, J.M., Lopes, M., and Foiani, M. 2002. Fork reversal and ssDNA accumulation at stalled replication forks owing to checkpoint defects. Science 297: 599-602.

Sommariva, E., Pellny, T.K., Karahan, N., Kumar, S., Huberman, J.A., and Dalgaard, J.Z. 2005. Schizosaccharomyces pombe Swi1, Swi3, and Hsk1 are components of a novel 
Szyjka et al.

S-phase response pathway to alkylation damage. Mol. Cell. Biol. 25: 2770-2784.

Stano, N.M., Jeong, Y.J., Donmez, I., Tummalapalli, P., Levin, M.K., and Patel, S.S. 2005. DNA synthesis provides the driving force to accelerate DNA unwinding by a helicase. Nature 435: $370-373$.

Szyjka, S.J., Viggiani, C.J., and Aparicio, O.M. 2005. Mrc1 is required for normal progression of replication forks throughout chromatin in S. cerevisiae. Mol. Cell 19: 691-697.

Takeda, T., Ogino, K., Matsui, E., Cho, M.K., Kumagai, H., Miyake, T., Arai, K., and Masai, H. 1999. A fission yeast gene, him $1(+) / \operatorname{dfp} 1(+)$, encoding a regulatory subunit for Hsk1 kinase, plays essential roles in S-phase initiation as well as in S-phase checkpoint control and recovery from DNA damage. Mol. Cell. Biol. 19: 5535-5547.

Takeda, T., Ogino, K., Tatebayashi, K., Ikeda, H., Arai, K., and Masai, H. 2001. Regulation of initiation of S phase, replication checkpoint signaling, and maintenance of mitotic chromosome structures during $S$ phase by Hsk1 kinase in the fission yeast. Mol. Biol. Cell 12: 1257-1274.

Tenca, P., Brotherton, D., Montagnoli, A., Rainoldi, S., Albanese, C., and Santocanale, C. 2007. Cdc7 is an active kinase in human cancer cells undergoing replication stress. J. Biol. Chem. 282: 208-215.

Tercero, J.A. and Diffley, J.F. 2001. Regulation of DNA replication fork progression through damaged DNA by the Mec1/ Rad53 checkpoint. Nature 412: 553-557.

Tercero, J.A., Longhese, M.P., and Diffley, J.F. 2003. A central role for DNA replication forks in checkpoint activation and response. Mol. Cell 11: 1323-1336.

Tourriere, H., Versini, G., Cordon-Preciado, V., Alabert, C., and Pasero, P. 2005. Mrc1 and Tof1 promote replication fork progression and recovery independently of Rad53. Mol. Cell 19: 699-706.

Travesa, A., Duch, A., and Quintana, D.G. 2008. Distinct phosphatases mediate the deactivation of the DNA damage checkpoint kinase Rad53. J. Biol. Chem. doi: 10.1074/ jbc.M801402200.

Ulrich, H.D. 2005. The RAD6 pathway: Control of DNA damage bypass and mutagenesis by ubiquitin and SUMO. ChemBioChem 6: 1735-1743.

Unsal-Kacmaz, K., Chastain, P.D., Qu, P.P., Minoo, P., Cordeiro-Stone, M., Sancar, A., and Kaufmann, W.K. 2007. The human Tim/Tipin complex coordinates an Intra-S checkpoint response to UV that slows replication fork displacement. Mol. Cell. Biol. 27: 3131-3142.

Viggiani, C.J. and Aparicio, O.M. 2006. New vectors for simplified construction of BrdU-Incorporating strains of Saccharomyces cerevisiae. Yeast 23: 1045-1051.

Weinreich, M. and Stillman, B. 1999. Cdc7p-Dbf4p kinase binds to chromatin during $\mathrm{S}$ phase and is regulated by both the APC and the RAD53 checkpoint pathway. EMBO J. 18: 5334-5346.

Xu, W., Aparicio, J.G., Aparicio, O.M., and Tavare, S. 2006. Genome-wide mapping of ORC and $\mathrm{Mcm} 2 \mathrm{p}$ binding sites on tiling arrays and identification of essential ARS consensus sequences in S. cerevisiae. BMC Genomics 7: 276. doi: 10.1186/1471-2164-7-276.

Yuzhakov, A., Turner, J., and O’Donnell, M. 1996. Replisome assembly reveals the basis for asymmetric function in leading and lagging strand replication. Cell 86: 877-886. 


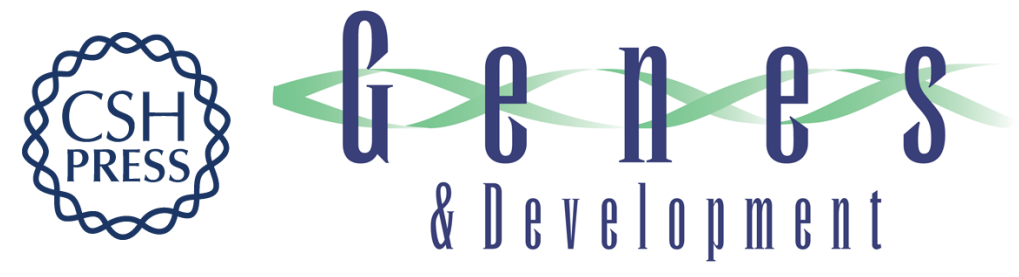

\section{Rad53 regulates replication fork restart after DNA damage in Saccharomyces cerevisiae}

Shawn J. Szyjka, Jennifer G. Aparicio, Christopher J. Viggiani, et al.

Genes Dev. 2008, 22:

Access the most recent version at doi:10.1101/gad.1660408

Supplemental http://genesdev.cshlp.org/content/suppl/2008/07/01/22.14.1906.DC1
Material

References This article cites 61 articles, 31 of which can be accessed free at: http://genesdev.cshlp.org/content/22/14/1906.full.html\#ref-list-1

License

Email Alerting Receive free email alerts when new articles cite this article - sign up in the box at the top Service right corner of the article or click here.

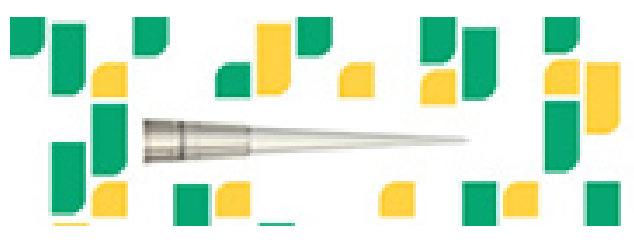

Focused on your science. 